UCRL-JC-113744

PREPRINT

\title{
Three-Dimensional Dynamic Thermal Imaging of Structural Flaws by Dual-Band Infrared Computed Tomography
}

\author{
N. K. Del Grande, K. W. Dolan, P. F. Durbin, M. R. Gorvad,
} B. T. Kornblum, D. E. Perkins, D. J. Schneberk, and A. B. Shapiro

This paper was prepared for submittal to the SPIE Proceedings, Vol. 1942, SPIE

April 15-16, 1993

Orlando, FL

April 1993

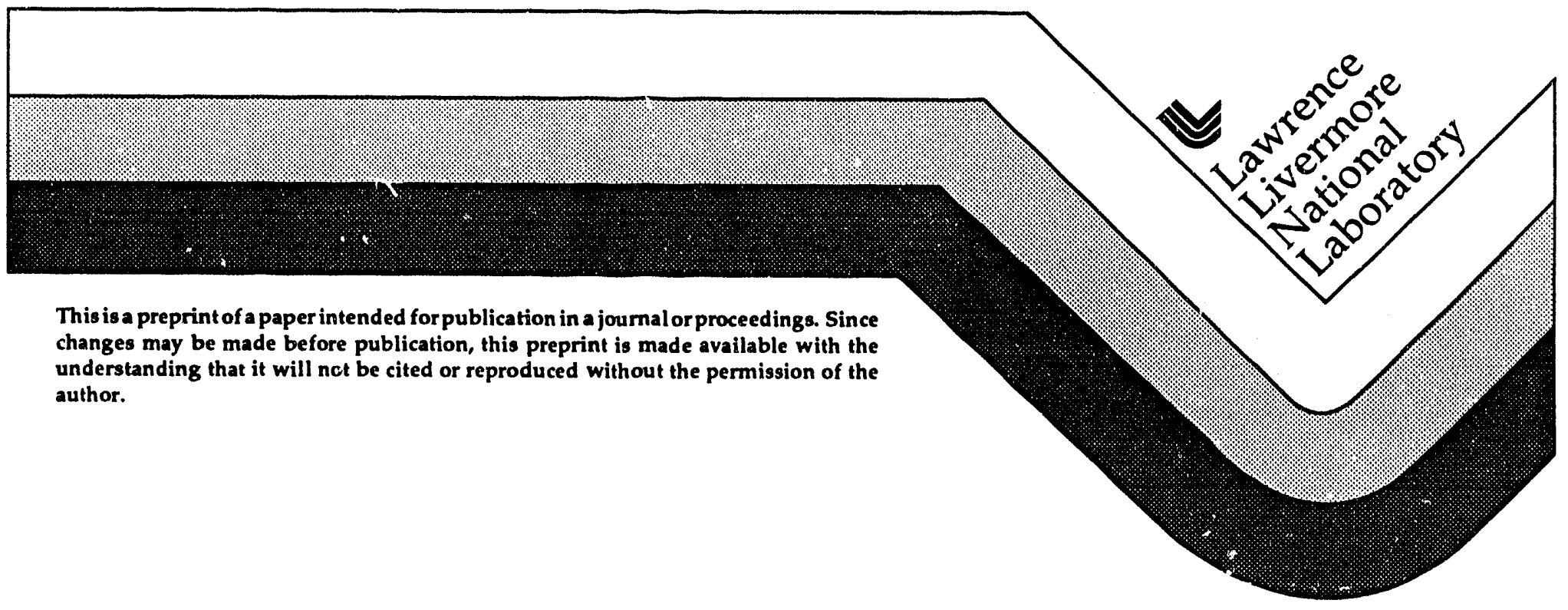




\section{DISCLAIMER}

This document was prepared as an account of work sponsored by an agency of the United States Government. Neither the United States Government nor the Uni versity of California nor any of their employees, makes any warranty, express or implied, or assumes any legal liability or responsibility for the accuracy, completeness, or usefulness of any information, apparatus, product, or process disclosed, or represents that its use would not infringe privately owned rights. Reference herein to any specific commercial products, process, or service by trade name, trademark, manufacturer, or otherwise, does not necessarily constitute or imply its endorsement, recommendation, or favoring by the United States Government or the University of California. The views and opinions of authors expressed herein do not necessarily state or reflect those of the United States Government or the University of Califomia, and shall noi be used for advertising or product endorsement purposes. 
Three-dimensional dynamic thermal imaging of structural naws

by dual-band infrared computed tomography

N. K. Del Grande, K. W. Dolan, P. F. Durbin, M. R. Gorvad, B. T. Komblum,

D. E. Perkins, D. J. Schneberk and A. B. Shapiro

Law ince Livermore National Laboratory

P. O. Box 808, Livermore CA 94550

\begin{abstract}
We discuss three-dimensional (3D) dynamic thermal imaging of structural naws using dual-band infrared (DBIR) computed procedures yield imprecise (or qualitative) infores single-band infrared images which are difficult to interpret. Standard procedures yield imprecise (or qualitative) information about subsurface flaw sites which are typically masked by surface patterns for flash-heated targets. We relate pioneered at LLNL to capture the time history of surface temperature difference demonstrated temperauure accuse thelate these patterns to the location, size, shape and depth of subsurface flaws. We have $\mathrm{ms}$, between images, during an $8 \mathrm{~s} \mathrm{cooling}{ }^{\circ} \mathrm{C}$, timing synchronizations of $3 \mathrm{~ms}$ (after onset of heat flash) and intervals of 42 history of an epoxy-glue disbond site in a flash-heated aluminum lap jeinzing the front (and br $k$ ) surface temperature-time causing damage to the Aloha Aircraft fuselage heated aluminum lap joint. This type of disbona played a significant role in micron), we located surface temperanure pattems the aged Boeing 737 jetliner. By ratioing DBIR images (near 5 and 10 the emissivity mask (from surface roughness variations). we weak heat flow anomalies at subsurface flaw sites) and removed dimensional, finite element computer code: TOPAZ3D. We compared measurements with calculations from the threecharacterize the lap joint disbond site spatial, bond quality, combined infrared, ultrasound and $x$-ray imaging methods to
\end{abstract}

\title{
1. INTRODUCTION
}

\subsection{Background and technical approach}

Previous applications of the dual-band infrared (DBIR) mechod developed at LLNL for underground and obscured object imaging and detection have depicted heat flow anomalies which produce distinguishable surface temperature differences from:

- geothermal aquifers under 6 to 60 meters of dry soil, 1.2

- cemetary walls, trenches and a building foundation under $80 \mathrm{~cm}$ of asphalt and debris, ${ }^{3}$

- buried mines, rocks and objects under 1 to $15 \mathrm{~cm}$ of disturbed sand, soil, or sod, 3.6

- sea ice thicknesses varying from 5 to $50 \mathrm{~cm}, 7,8$

- subsurface disbond and delamination sites in aircraft parts at 1 to $2 \mathrm{~mm}$ depths. 7

In 1992, LLNL began a FAA Technical Center funded program to demonstrate DBIR precise temperaure mapping as a tool for aging aircraft inspection. The DBIR method uses ratios of two thermal infrared (IR) images to locate subsurface structural delaminations in composite material patches. These disbond he have located epoxy-glue disbonds in aluminum lap joints and signatures unlike those associated with surface roughness differencets, coating sites have thermal and emissivity-related The focus of this paper is to characterize interior flaws (e.g. their size, coating discontinuities or other heterogeneous effects. select the lap joint as an example for detsiled investis (e.g., their size, shape and depth) in flash-heated aircraft structures. We causing damage to the Aloha Aircraft fuselage on the aged Berein, since lap joint disbonds played a significant role in

\subsection{Dual-band infrared (DBIR) concept and physical principles 9}

The dual-band infrared (DBIR) concept which we describe below has proven to be useful for image interpretation of certain types of subsurface flaws in aging aircraft structures. It exploits a property of Planck's radiation law thas applies for emitted radiation from a surface at lemperature $T$ (Kelvin), near $T_{0}$ (typically $288 \mathrm{~K}$ or $15^{\circ} \mathrm{C}$ ). For surface temperatures within about $20^{\circ} \mathrm{C}$ of $\mathrm{T}_{0}$, the radiant emittance is proportional to surface emissivity $\left(\varepsilon \lambda\right.$ times $\left(T / T_{0}\right)$ raised to the power of $50 / \lambda$, at wavelength $\lambda$ in $\mu \mathrm{m} .{ }^{9}$ This propeny has been applied quile successfully for distinguishing temperalure signals from spatially varying surface emissivity noise in a variety of applications mentioned above. 


\subsection{DBIR image ratios used for temperature map}

The short wavelength band (SWB) image at $5 \mu \mathrm{m}$ and the long wavelength band (LWB) image at $10 \mu \mathrm{m}$, are ratioed to produce a temperature map as follows:

(1)

$$
\text { SWB } / \text { LWB }=\left(\varepsilon_{5}\right) /\left(\varepsilon_{10}\right) \cdot\left(T / T_{0}\right)^{5} \text {. }
$$

The temperature map enhances surface temperature differences and minimizes surface emissivity variations for coated aircraft surfaces which have nearly the same emissivity at $5 \mu \mathrm{m}$ and $10 \mu \mathrm{m}$.

\subsection{DBIR image ratios used for emissivity-ratio map}

Also, we produce an emissivity-ratio map using image ratios which cancel out the effect of surface temperature: $\cdot .10$

(2)

$$
(L W B)^{2} /(\text { SWB })=\left(\varepsilon_{10}\right)^{2} /\left(\varepsilon_{5}\right)=\varepsilon \text {. }
$$

The emissivity-ratio map entances the emissivity-ratio differences between painted (or coated) and uncoated aluminum aircraft structures to remove the effect of surface clutuer. It depicts sites with the same (or very different) surface emissivity ratios at the same (or very different) grey scale (or cclor-coded) levels, independent of their surface temperature. It is useful, in combination with the temperature map to locate surface temperature patterns (generated by weak heat flow anomalies at subsurface flaw sites) and remove the emissivity mask (from surface roughness differences, coating discontinuities or other heterogeneous effects.

\section{RATIONALE FOR PRESENT STUDY}

\subsection{Transition from previous studies}

We address key technical issues: fast-capture thermography, flaw depth detection and clutuer-free interpretation applied to disbond sites in an aluminum lap joint. We use the differences in the time history of air site minus the epoxy-glue site surface temperature and first derivative of the surface temperawure with respect to time) 10 characterize the disbond physical properties. We compare measurements with calculations based on the three-dimensional implicit finite element computer code: TOPAZ3D used for transient or steady-state heat transfer analysis. We capture surface temperature slices every $42 \mathrm{~ms}$ and record simultaneous front and back surface temperature scans from 0 to 8 seconds after a synchronized flash from our heat lamps. These results are compared with calculations.

\subsection{Use of multisensor technologies}

We investigate multisensor technologies (infrared, ultrasound and $x$ rays) to provide synergistic results for characterizing subsurface defects in aircraft parts. We use of infrared sensors to image the dynamics of heat transfer anomalies, ultrasound to image variations in bond quality, and $x$ rays to image material differences between air and epoxy glue at the disbond site. This provides a robust inspection technique for characterizing the nature of subsurface flaws in relation to their heat transfer properties, their bond qualities and their material differences. Also, we use computer processing techniques which parallel our experimental efforts to characterize the 3D heat transfer anomalies generated by subsurface defects.

\section{MEASUREMENT PROCEDURE}

\subsection{Application}

We are developing a capability for dynamic thermal tomography using dual-band infrared (DBIR) imaging for nondestructive inspection (NDI) technology as part of the FAA Technical Center's National Aging Aircraft Research Program. We describe an inspection technique to provide an early warning of hidden defects in aircraft structures such as voids, cracks, delaminations, inclusions, disbonds or areas of comosion in metallic lap juints, riveted panels and composite patches.

\subsection{Dual-band infrared (DBIR) temperature and emissivity-ratio maps}


We use the digitized SWB and LWB infrared images recorded with the Agema 880 DBIR camera system and Burst Recording Unit (BRU) as input to a Silicon Graphics Inc. (SGI) Workstation. This procedure provides apparent temperature images recorded at wavelengths centered near $10 \mu \mathrm{m}(\mathrm{LWB})$ and $5 \mu \mathrm{m}$ (SWB), for comparison with temperature map images derived from Equation (1) and emissivity-ratio map images derived from Equation (2).

\subsection{Infrared computed tomography}

We expect infrared computed tomography to be achievable with resources developed at LLIV for other applications. By synchronizing the heat source such as a series of flash lamps (or a flying spot laser) with the Agema 880 DBIR camera and digital image processing system to record and process images taken at intervals of $42 \mathrm{~ms}$. Surface thermal patterns have spatial and time variations that characterize the location, size and depth of subsurface defects in the host material. Calculations will be used to reconstruct 3D images of will be used to reconstruct 3D images of structural defects. We are addressing the inherent problems associated with singleband dynamic thermal tomography using the DBIR tochnique.

To identify small temperature differences from weak heat flow anomalies at the sites of deep structural defects, one must first remove the order of magnitude larger apparent temperature differences from surface emissivity noise. There are no algorithms able to do this for a suigle-band system. The alternative is elaborate surface preparation (using paint, paper or powder). This raises the sensitivity threshold for weak heat flow detection.

The DBIR imaging technique provides a factor of ten better temperature-difference sensitivity, accuracy and precision. This rechnique offers improved image clarity and interpretability when we use ratios of 5 and $10 \mu \mathrm{m}$ IR images to remove clutter and enhance thermal contrast. In addition, the DBIR method maps corrected temperature pauterns (associated with weak heat flow anomalies at defect sites) and removes spatially varying surface emissivity noise (associated with surface roughness differences, coating discontinuities or other inhomogeneous effects).

\section{Calculation PROCedure}

\subsection{Use of TOPAZ3D model 10}

Thermal analysis of the Boeing lap joint test specimen was performed using TOPAZ3D. TOPAZ3D is a three-dimensional implici Thatite element computer code for transient or steady state heat transfer analysis. A variety of time or temperaure dependent boundary conditions may be specified, including temperature, flux, convection, and radiation. Material properties may be temperature dependes either isotropic or orthotropic. TOPAZ3D has been extensively used at LLNL for more than a decade.

The finite element mesh of the lap joint test specimen, which takes advantage of half-symmetry, consists of 4032 brick elements (se Figure 1). We used four elements through the thickness of each aluminum plate and two elements layers of epoxy or air. Extra mes discretization across the plate surfaces is used at the epoxied edges.

$-$

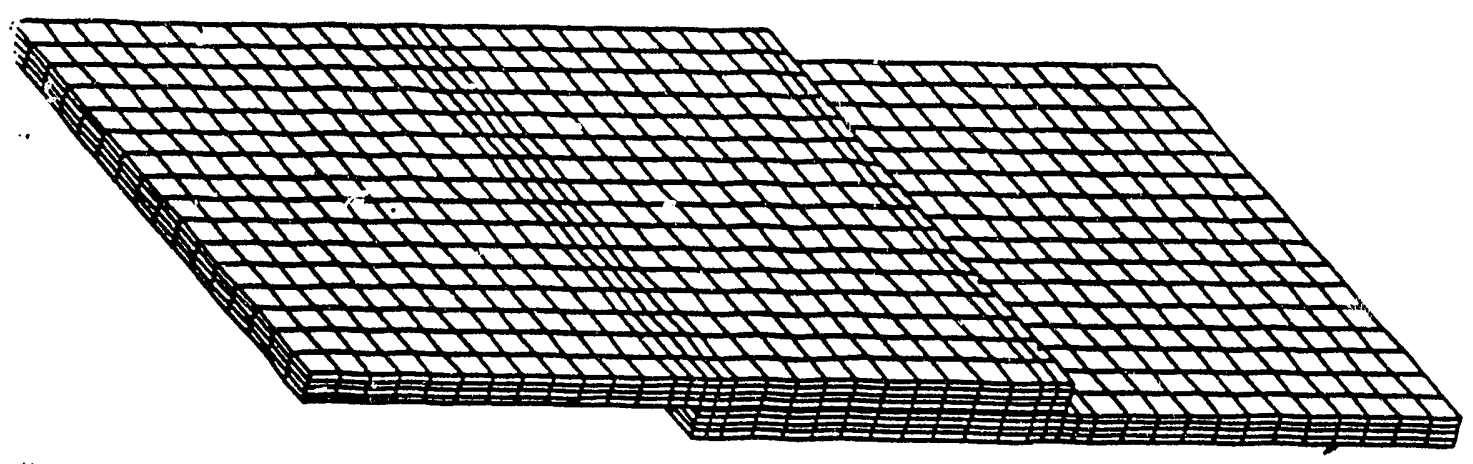

Figure 1. Finite element mesh of test specimen used to calculate heat flow anomalies generated on the front and back surfaces of an aluminum lap joint where a $0.1 \mathrm{~mm}$ air gap at the disbond site replaces a $0.1 \mathrm{~mm}$ epoxy-glue layer at the high quality bond site. 
The flash-lamp heat pulse is approximated as a constant heat flux applied uniformly over the front surface of the test specimen. The for heating is $4.2 \mathrm{~ms}$ which corresponds to the duration of the flash-! amp pulse in the experiment, however we realize that the actual pulse is neither constant nor uniform. In determining the magnitude of the applied flux we had to estimate the absorptance of the tes specimen and the fraction of emitted flash-lamp light which reaches the test specimen. Radiation heat loss to the ambient environm included in the calculation, althcugh it is admittedly a small quantity. Convection and conduction to the surroundings are negligible. We have confidence in the accuracy of the temperaure field calculated by TOPAZ3D. The TOPAZ3D result for the peak front surfac temperature compared well with the temperature calculated from a 1-D closed-form solution. ${ }^{11}$ In addition, the finite element mesh was refined to show that convergence had been reached. The penetration depth of the flash-lamp heating pulse into the aluminum pla determined to be 60 mils ( 0.06 inches) at the end of the pulse. ${ }^{12}$

TOPAZ3D results are shown later in the text for comparison with measurement. We simulate an experiment where two flash lamps used to illuminate the test specimen, whose surfaces had been coated with black paint to enhance absorptivity. The trend of the simu result parallels the trend of the experimental data quite well. However, in the numerical simulation, the test specimen equilibrated to uniform temperature more rapidly than in the experiment. This discrepancy is because the material properties used in the TOPAZ3D .calculation were estimated, hence they differ from the actual properties of the test specimen. We plan to resolve the property differen in future TOPAZ3D calculations. Table 1 lists the material properies used for the current result.

Table 1. Material properties used as input for TOPAZ3D calculation.

$\begin{array}{llll}\text { Material } & \begin{array}{l}\text { Thermal } \\ \text { Conductivity } \\ \left(\mathrm{W} / \mathrm{m}^{2} \mathrm{~K}\right)\end{array} & \begin{array}{l}\text { Specific } \\ \text { Heat } \\ (\mathrm{J} / \mathrm{kg} \mathrm{K})\end{array} & \begin{array}{l}\text { Density } \\ \text { in } \\ \mathrm{kg} / \mathrm{m}^{3}\end{array} \\ \text { Aluminum } & 200 . & 837 . & 2790 . \\ \text { Epoxy } & 0.1946 & 1172 . & 1210 . \\ \text { Air } & 0.025 & 1000 . & 1.29\end{array}$

\subsection{Algorithms under consideration for three-dimensional reconstructions}

We discuss the possibilities for developing volumetric infrared computed tomography (IRCT) with a review of the $x$-ray case. before we propose reconstruction algorithms, we will analyze the volumetric information in pulse-heated, cooling cycle images of objects. It is our intention to make as much connection with the $x$-ray case as possible, and on this basis utilize the work already available for $x$-ray and gamma-ray computed tomography (CT).

Computed tomography reconstruction algorithms calcuiate volumetric information from detected integrations of energy which has traveled through the object. The canonical case for $x$-rays is the 3rd generation scan of an object, and we consider a single $x$-ray transmission measurement. For example, we consider a cone-beam source with a spot size which is small enough to make a 'point-source' approximation reasonable. The object is a 3D function, which has linear attenuation coefficients $\mu(E, Z, r, v)$, which vary with: the 3D position, $v$ (a volume element or voxel), the energy of the radiation inpinging on that voxel, $E$, the effective atomic number, $Z$, and the average density of the voxel, $r$. The interaction of the object function with the primary radiation from a cone-beam source follows Beer's Law, as shown in equation (4):

$$
N_{p}(E, d, q)=N_{p} 0(E, d, q) \exp \left(-\int \mu(E, Z, r, v) d\left(\left(s(q)+I_{d} u_{d}(q)\right) \cdot v\right) d v\right)
$$

where the equation for the ray pach is $s(q)+L_{d} u_{d}(q)$, where $s(q)$ is the position of the source relative to the objcct rotation, Id the distance from source to detector, and $u_{\mathrm{d}}(q)$ the direction cosines of the path betwcen source and detector, again relative to the object rotational angle.

For gauging, and quantitative radiography, a measurement of $\mathrm{N}_{\mathrm{p} O}$ is acquired and employed to obtain the transmission $T_{\mathrm{P}}$, and the absorptance AP, as indicated below: 


$$
\begin{aligned}
& \left.\operatorname{TP}(E, \mathrm{~d}, \mathrm{q})=\operatorname{NP}(E, \mathrm{~d}, \mathrm{q}) / \mathrm{N}_{\mathrm{p} O}(E, \mathrm{~d})\right)=\exp \left(-\int \mu^{\prime}(E, Z, r, \mathrm{v}) d\left(\left(\mathrm{~s}(\mathrm{q})+\mathrm{I}_{\mathrm{d} u \mathrm{~d}}(\mathrm{q})\right)-\mathrm{v}\right) d \mathrm{v}\right) \\
& \text { - } \quad \operatorname{PP}(E, d, q)=-\ln \left(T_{P}(E, d, q)=\int \mu(E, Z, r, v) d\left(\left(s(q)+l_{d} u_{d}(q)\right)-v\right) d v\right.
\end{aligned}
$$

For CT :anning, the acquisition of $\operatorname{AP}(E, d, q)$ for an angular range of $\pi$ (for parallcl beam data), or $2 \pi$ (for fan or cone data), can be reconstructed into a per-voxel image of the object function.

The input data to a CT reconstruction is a set of line integrals, over some set of transmission lines through the object, determined by the source distribution function. The many rotational views input to the reconstruction algorithm are used to reconstruct the inner contents. It is one of the key features of the $x$-ray case that the linear attenuation coefficient is the product of the density and the chemical formula and admits a straightfonward interpretation.

Infrared observations of the aluminum lap joint cooling cycle is different and thus presents different opportunities for possible volumetric applications. The heat conduction equation

$$
(\partial \theta / \partial t)=\alpha(\partial \theta / \partial z)
$$

has the following solution

$$
\theta(z, t)=\theta(0, a) e^{-k z} \sin (2 \pi v t-k z)
$$

or,

$$
[\theta(z, t) / \theta(0, a)]=e^{-k z} \sin (2 \pi u t-k z)
$$

where:

$$
\therefore \quad \begin{aligned}
& k=\operatorname{sqn}(\pi v / \alpha) \\
& z=\operatorname{depth}(\mathrm{cm}) \\
& t=\operatorname{time}(\sec ) \\
& v=\text { trequency }(1 / \mathrm{sec}) \\
& \alpha=\operatorname{diffusivity} \\
& a=\text { time when temperature is maximum } \\
& \theta=\text { deviations from mean temperature }(C)
\end{aligned}
$$

The temperature at the surface of an object that has been changed by rapid heaing can be viewed as the integration of the cooling from the depths of the material dissipa $\mathrm{g}$ into the surrounding medium. After the heat source is off, the temperature at the surface of the material measures the incegration of the heat dissipating from the inner layers to the surface, and depends upon the heat diffusivity of the materials between a selected layer and the surface. Indeed, the heal flux observed at the surface of the object $f(x, y, 21, t)$ observed through the cooling cycle (integrated through time segment $q$ ) can be related to the deviations from the mean temperawure of the inner layers;

$$
f(x, y, z l, t)=\iint \theta(z, t) \partial z \partial t=\theta(0, a) \iint e^{-k z} \sin (2 \pi v t-k z) \partial z \partial t
$$

The first issue in obtaining these measurements is the ability to know the penetration depth of the heat pulse, and the time at which the maximum temperature was obtained. We propose to observe the specimen with two cameras at the same time. The significance of this arrangement is in the measurement of $\theta(0, a)$ for the cooling cycle data on both sides and recording the depth of penetration of any heat pulse. We will atempt to construct line integral data with these measurements and make use of existing algorithms.

\section{RESULTS}

\subsection{Lap joint disbond site viewed with infrared, ultrasound and $x$-ray images}

In Figure 2a, we see a diagram of the lap joint with features similar to what is used on a Boeing commercial jetliner. There is a rectangular $(0.1 \mathrm{~mm}$ thick) air layer representing the disbond site. Figure $2 \mathrm{~b}$ shows a $10 \mu \mathrm{m}$ IR image of the disbond site 
the surface of which is 0.4 or $0.5^{\circ} \mathrm{C}$ warmer (where it was flash heated) than the epoxy-glue sites which surround it. In Figure $2 c$ is the ultrasound image which shows a beuer bond quality in the epoxy region, indicated by lower signal values (higher values to the right side of the color bar) compared to the higher signal values in the epoxy free region.. Figure $2 d$ shows reverse geometry $x$ rays at $45 \mathrm{keV}$ which transmit differently through two overlapping $(0.9 \mathrm{~mm}$ thick $)$ Al sheets which sandwich the $0.1 \mathrm{~mm}$ air gap than the equally thick epoxy-glue layer.

\subsection{Surface temperatures from anomalous heat flows at lap joint disbond site}

In Figure 3, we see front-surface (top images) and back-surface (bollom images) of apparent temperatures at $10 \mu \mathrm{m}$ (a-d) and 5 $\mu \mathrm{m}(\mathrm{e}-\mathrm{h})$ recorded at $0,2,4$ and 8 seconds after flash-heating the front surface. The front and back images were recorded simultaneously with the 10um IR scanner in the front (flash lamp side) and the $5 \mu \mathrm{m}$ IR scanner in the back. The maximum thermal contrast between air and epoxy-glue layers occurred at approximately 2 seconds. The front surface disbond site stayed warmer longer (and the back surface remained cooler longer) than ambient bonded sites because air is a good insulator. It provides a heat sink, which retains heat from the flash-heated front surface and delays heat from reaching the back surface.

\subsection{Lap joint temperature and emissivity-ratio images}

In Figure 4, we note subtle differences between the lap joint apparent temperature-difference images recorded at $10 \mu \mathrm{m}$ (a), 5 $\mu \mathrm{m}$ (b), and with DBIR image ratios which produce a temperature map enhancing thermal contrast (c). The emissivity-ratio map (d) is nearly constant, unlike the temperaure maps (a), (b), and (c) for an Al target painted black to maximize heat absorptivity. Both the $10 \mu \mathrm{m}$ and the $5 \mu \mathrm{m}$ images were taken from the front (flash lamp side). We obtained about three times the thermal contrast (between air and epoxy-glue sites) using black paint rather than white powder. Most aircraft parts are expected to have surfaces which are painted or coated with sealants to impede corrosion.

\subsection{Comparison of measurements with calculations}

Surface temperature differences which separate air disbond sites from epoxy-glue bonded sites peak about 2 seconds after nashheating the lap joint on the front side according to our results (see Figure 5a). A fifth order polynomial fit was made to the averaged data for air disbond and glue bond sites scanned at the front with the LWB detector and at the back with the SWB detector Figure 5b). The two detoctors were synchronized with the flash unit and recorded nearly simultaneously (within 10 $\mathrm{ms}$ ). The fifth order polynomial fits to data not shown (Figure Sb) provided a good fit to temperature difference data (Figure 5a) and the time derivative of temperature data (Figure 5c).

Calculations of early response data are shown in Figure 6 together with the front surface and back surface air minus glue site temperature differences. There is good qualitative agreement, but further refinement is needed to improve the input parameters for the TOPAZ3D model.

\section{SUMMARY AND CONCLUSIONS}

We demonstrated the capability of the DBIR technique to precisely locate weak heat flow anomalies from a lap joint disbond site with a layer of air $(0.1 \mathrm{~mm}$ thick) bounded above and below by bonded epoxy glue sites and sandwiched between two ( 0.9 mm thick) aluminum sheets. Also, we converted scaled DBIR image ratio data to temperature maps which enhance thermal contrast and emissivity-ratio maps reject sites with surface roughness variations, coating differences and other heterogeneous
effects.

The dual-band technique has the following advantages over a single band techniques:

- provides five to ten times better temperature accuracy and precision,

- uses image ratios to remove clutuer and enhance thermal contrast,

- decouples temperature from spatially varying surface emissivity noise, and

- locates weak heat flow anomalies from subsurface flaw sites.

We used fast-captured surface temperature images to study the temperature versus time history of subsurface defect sites from a ..lap joint like the structure which was largely responsible for the fuselage problem on the Aloha Airlines Boeing 737 jetliner. We combined three multisensor techniques to charactize the lap joint disbond site, namely: infrared, ultrasound and $x$ rays. Thaso lochniquos provided information about heal transfor anomalios, the bond quality and matorial difroroncos at the disbond
site. 
Our future plans are to use TOPAZ3D calculations to model the dynamic relationships between the flaw site surface temperature versus time and the subsurface flaw size, shape and depth. We will adapt the appropriate DBIR procedures based on oir experiences which have successfully developed $x$-ray and gamma-ray computed tomography. These procedures will be test it to determine the three dimensional heat transfer properties which lead to circular thermal images on back surface scans of lap joint disbond sites compared to rectangular thermal images on front surface scans taken at the same time.

\section{ACKNOWLEDGEMENTS}

This work was performed by LI.NL under the auspices of DOE contract number W-7405-ENG-48 for the DOT/FAA Technical Center order The autiors acknowledge the ultrasonic test conducted by Steve Benson, and the reverse geometry $x$-ray test conducted by Richard Albert at Digiray Corp., valuable technical discussions with Graham Thomas, Susan Crawford and Harry Martz, and the overall support of Satish Kulkami.

\section{REFERENCES}

1. N. Del Grande, "Airborne and Field Temperature Surveys Compared At Long Valley KGRA, California", Geothermal Resounces Council Transactions 5 , 71 (1978).

2. N. K. Del Grande, "Airborne Temperature Survey Maps of Heat Flow Anomalies for Exploration Geology", Broceeding of Intemational Symposium on Remote Sensine of Environment. Second Thematic Conference on Remote Sensing for Exploration Geology Dec. 1982. Reprinted in Geothermal Resources Council Bulletin 14, p.3, Mar. 1985.

3. N. K. Del Grande, G.A. Clark, P.F. Durbin, DJ. Fields, J.E. Hemandez and R.J. Sherwood, "Buried Object Remote Detection For Law Enforcement", Surveillance Technologies, SPIE Vol. 1479, 335 (1991).

4. N. K. Del Grande, "Temperature Evaluated Mine Position Survey (TEMPS) Application of Dual Band Infrared Methodology", Broceedings of the 1990 Meetine of the IRIS Specialiv Group on Passive Sensors. IRIAERIM sponsored symposium, March 1990

5. N.K. Del Grande, "Sensor Fusion Methodology for Remoce Detection of Buried Land Mines", Broceedings of the 3rd National Sympesium on Sensor Fusion. Orlando, FI, Vol. 1, IIAC/ERIM, p.407, August 1990. 6. Nancy Del Grande, "Airbome Detection Of Buried Minefields", Energy and Technology Review, University of California LL]
Report.

UCRL-52-000-91-12,9 (1991).

7. N.K. Del Grande, P.F. Durbin and D.E. Pertins, "Dual-Band Infrared Imaging Applications: Locating Buried Minefields, Mappin Sea Ice, And Inspecting Aging Aircraft", In Proceedings: Quantitative Nondestructive Evaluation Conference. San Diego. Ca. Juiy
1992 (to be published).

8. John E. Lewis, Nancy Del Grande, Ian McKendry, Philip Durbin and Mati Lepparanta, "Thermal Mapping" in ERS-1

Baltic Sea Jce Calibration/Validation Post-E IDeriment_Repon/Pipor/Finland. Finnish Institute of Marine Research Report 1992 (9 Ed. Matui Lepparanta and Mikko Lensu, Helsinki (1992).

9. L. A. LeSchack and N. K. Del Grande, "A Dual-Wavelength Thermal Infrared Scanner As A Potential Airbome Geophysical Exploration Tool", Geophysics 41.1318 (1976).

10. Arthur B. Shapiro, "TOPAZ - A three-dimensional finite element heat transfer code, Lawrence Livermore Laboratory Repons UCID-20484, August 1985.

11. James H. VanSant, Conducti in Heat Transfer Solutions, Lawrence Livermore Laboratory Reporr UCRL-52863, August 1983.

12. T. R. Goodman, The Heat Balance Integral and It's Application to Problems Involving a Change of Phase. Trans. ASME, Feb. 
(a)

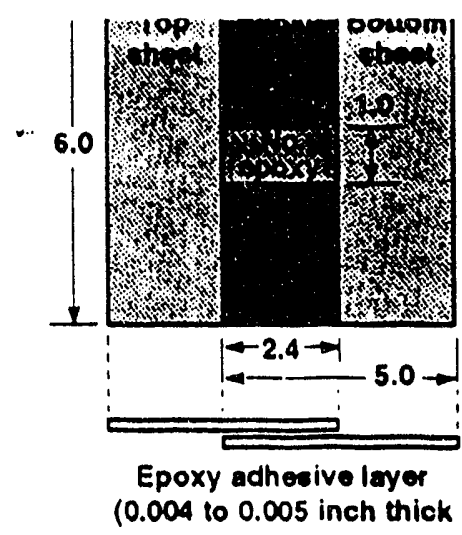

(b)

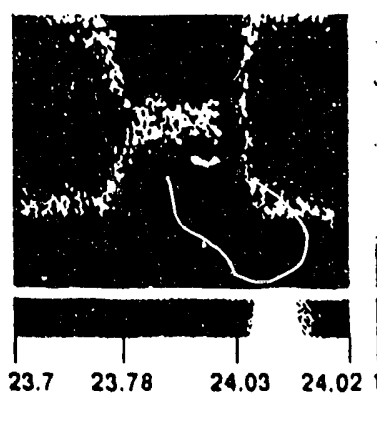

(c)

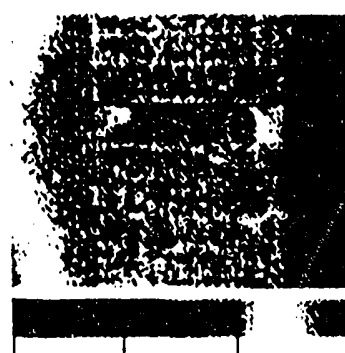

(d)

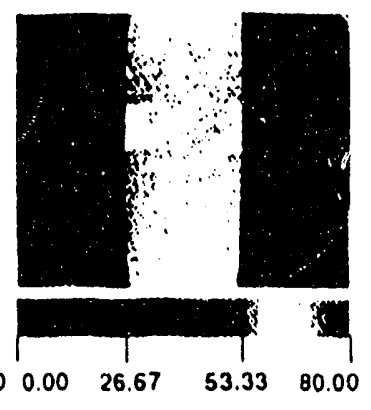

Figure 2. Lap joint disbond sample (a) configuration drawing, (b) infrared image, (c) ultrasonic image, (d) $x$-ray image.

(a)

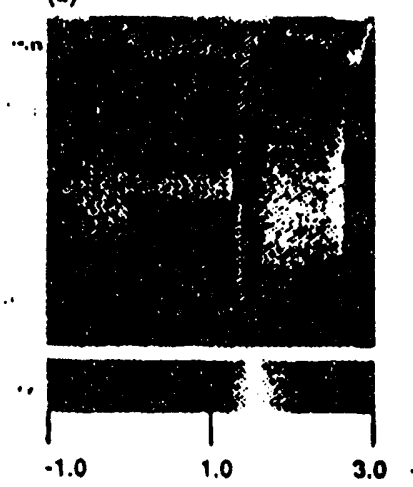

(๑)

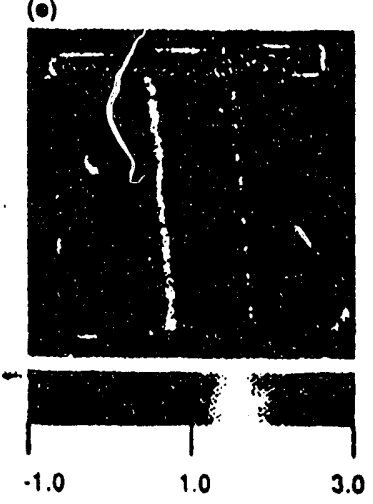

(b)
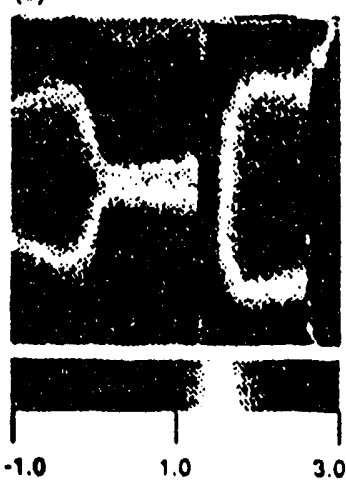

(n)

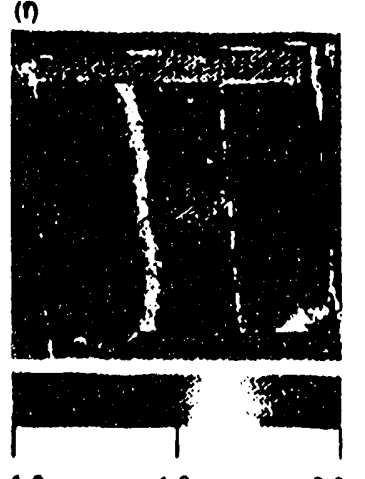

(c)

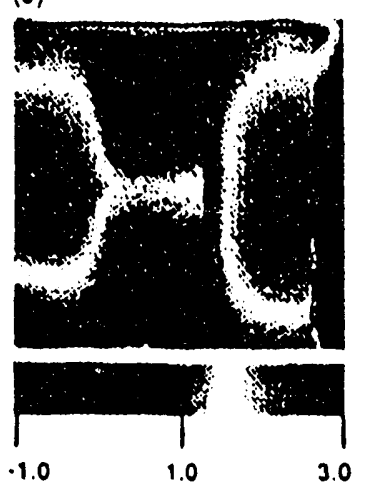

(g)

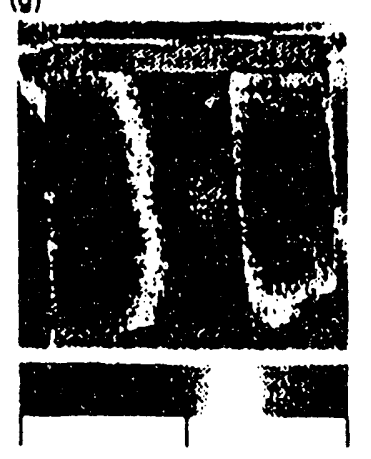

(d)

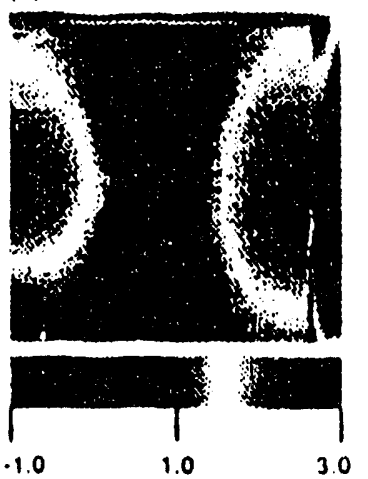

(n)

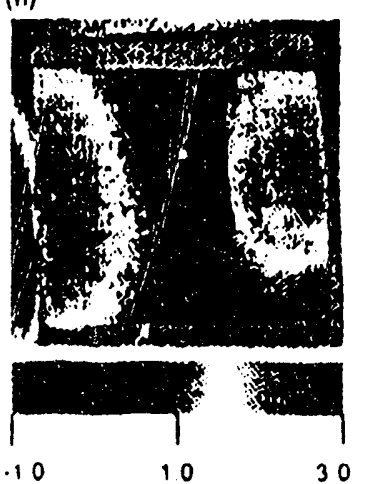

Figure 3. Infrared image time sequence with front heating and long-wave band $(10 \mu \mathrm{m})$ imager on same side as flash lamp heating source at (a) 0 seconds, (b) 2 seconds, (c) 4 seconds, and (d) 8 seoonds after flash, and with short-wave band $(5 \mu \mathrm{m})$ imager on opposite side of sample from flash heating source at (e) 0 seconds, (f) 2 seconds, (g) 4 seconds, and (h) 8 seconds after flash. 
(a)

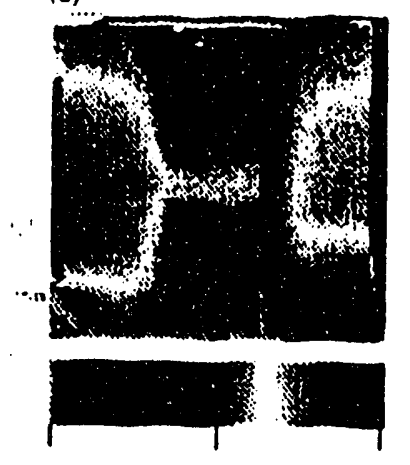

(b)

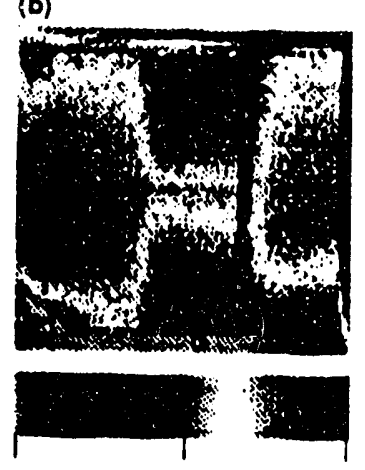

(c)

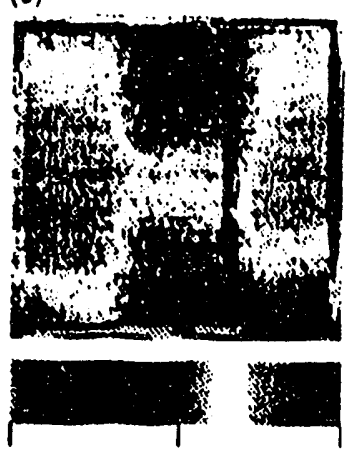

(d)

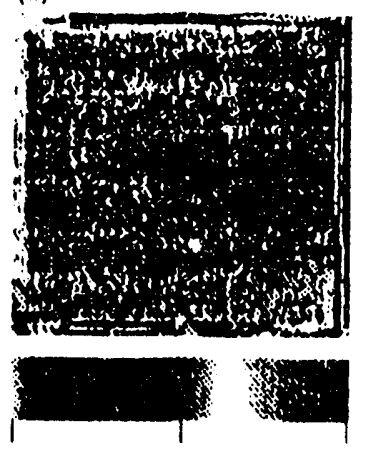

Figure 4. Infrared image of lap joint disbond sample with front surface flash heating and both imagers on same side of sample as heating source: (a) long-wave band ( $10 \mu \mathrm{m})$ imager, (b) short-wave band $(5 \mu \mathrm{m})$ imager, (c) temperature map, and (d) emissivity-ratio map.

(a)

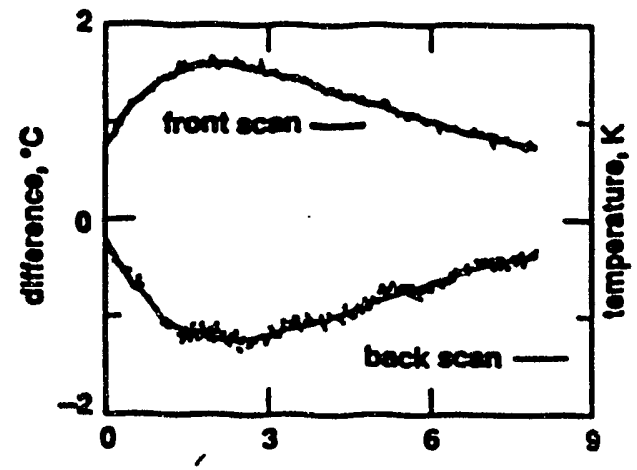

(b)

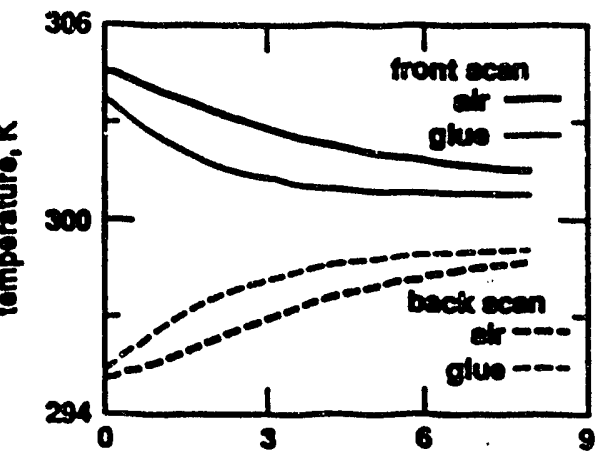

(c)

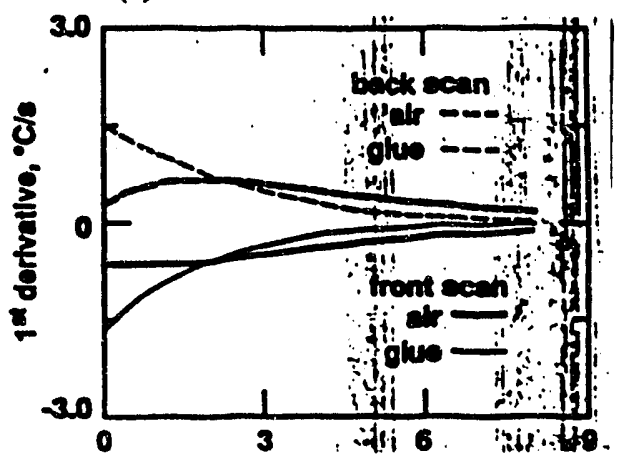

Figure 5. (a) Measured surface temperature difference between disbond site and ambient site on front an back surfaces, (b) fifth order polynomial fit to apparent temperature for front and back surface data, and (c) first derivative with respect to temperature for the fitted curve in 5(b). 
(a)

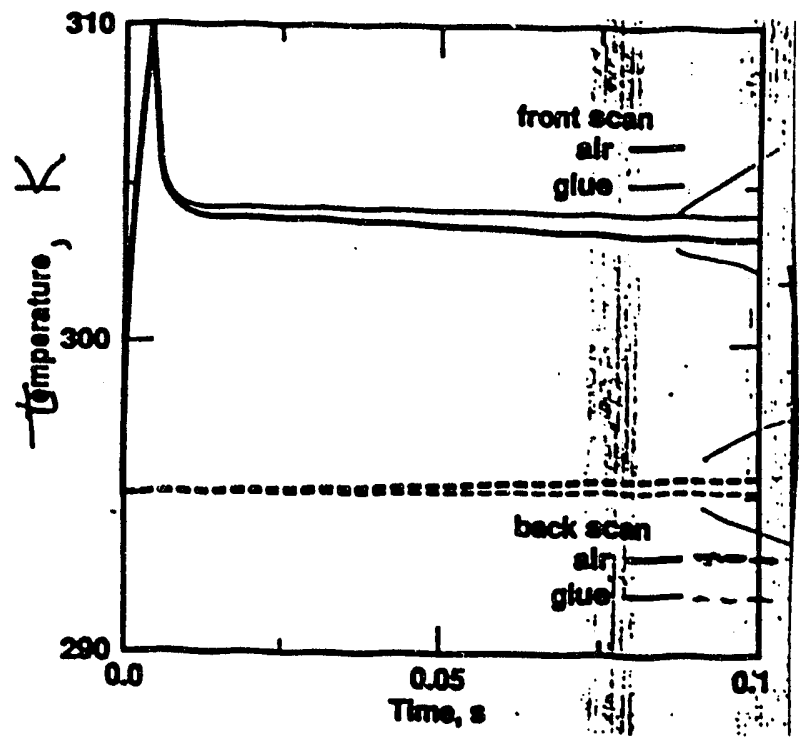

(b)

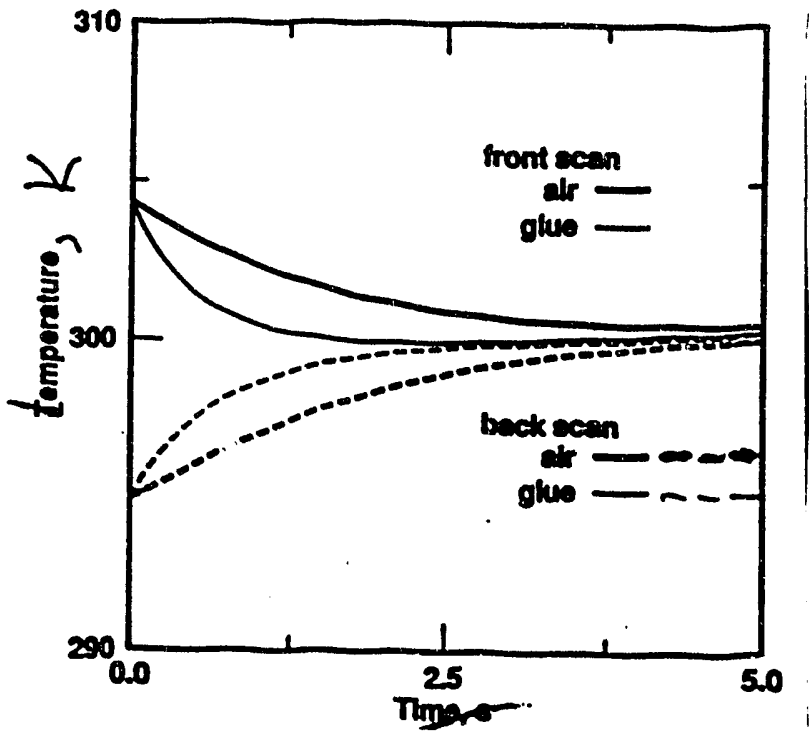

Figure 6. Results of themıal response calculations for flash heating of lap joint disbond sample at (a) early times, 0.0 to 0.1 seconds, and (b) later times, 0.0 to 5.0 seconds, for comparison to measured data in Figure 5(b). 
DATE FILMED $11 / 02 / 93$ 
